\title{
ASSOCIATION BETWEEN RESPIRATORY PATTERN AND MANDIBULAR MORPHOLOGY
}

\author{
ASSOCIAÇÃO ENTRE O PADRÃO RESPIRATÓRIO E A MORFOLOGIA MANDIBULAR
}

\author{
Flavio Cotrim-Ferreira * \\ Karyna Martins do Valle-Corotti * \\ Patricia de Medeiros Loureiro Lopes ** \\ Tatiana Helena Junqueira ** \\ Jessica Regina Stocco ***
}

\begin{abstract}
Introduction: The present study investigates the relationship between respiratory patterns and mandibular morphology. Methods: The study sample comprised 100 pre-orthodontic patients ranging from 8 to 13 years of age. The subject sample was evaluated by clinical examination and lateral cephalometric radiographs. A clinical examination of respiratory patterns categorized the subjects as mouth breathers (Group $\mathrm{M}, \mathrm{n}=52$ ) and nasal breathers (Group $\mathrm{N}, \mathrm{n}=48$ ). Results: The Student $\mathrm{t}$ test revealed a statistically significant relationship $(\mathrm{p}<0.05)$ between Group $\mathrm{M}$ and deep antegonial notch and greater lower anterior facial height. Conclusions: The results of this study suggest that deep mandibular antegonial notch and vertically directed growth pattern are more prominent in individuals who are mouth breathers.
\end{abstract}

DESCRIPTORS: Mouth breathing • Orthodontics • Mandible

\section{RESUMO}

Introdução: Este estudo investiga o relacionamento entre os padróes respiratórios e a morfologia. Métodos: A amostra do estudo foi formada de 100 pacientes pré-ortodônticos cuja idade variou de 8 a 13 anos. A amostra foi avaliada através de exame clínico e das radiografias cefalométricas laterais. Um exame clínico dos padrōes respiratórios categorizou os sujeitos entre aqueles que são respiradores bucais (Grupo M, $\mathrm{n}=52$ ) e respiradores nasais (Grupo N, $\mathrm{n}=48$ ). Resultados: O teste t de Student revelou um relacionamento estatisticamente significativo $(\mathrm{p}<0.05)$ entre o Grupo $\mathrm{M}$ e o ponto antegonial profundo e uma altura facial anterior mais baixa. Conclusóes: os resultados deste estudo sugerem que o ponto antegonial profundo e o padrão de crescimento direcionado verticalmente são mais proeminentes em indivíduos que são respiradores bucais.

DESCRITORES: Respiração bucal • Ortodontia • Mandíbula

\footnotetext{
*Associate Professors, Department of Pediatric Dentistry and Orthodontics, University of Sáo Paulo City (UNICID).

${ }^{* *}$ Graduate student of Master Degree, Department of Pediatric Dentistry and Orthodontics, University of Sáo Paulo City (UNICID).

*** Graduate student, Department of Pediatric Dentistry and Orthodontics University of São Paulo City (UNICID).
} 


\section{INTRODUCTION}

The association between the respiratory patterns and craniofacial development has been debated and investigated from various approaches (Ali et al. ${ }^{1}$ 2005, Lambrechts et al. ${ }^{7}$ 1996). McNamara ${ }^{9}$ (1981) illustrated the potential interaction between alterations in respiratory function and craniofacial growth pattern. Ung et al. ${ }^{12}$ 1990, studied the respiratory patterns and their effects on dentofacial development and observed that mouth breathing was associated with increased anterior facial height and mandibular plane angles, while the vertical dentofacial morphology was observed by Fields et al. ${ }^{4}$ (1991) in a sample with increased nasal resistance and mouth breathing.

Linder-Aronson, et al. ${ }^{8}$ (1986), Kerr et al. ${ }^{5}$ (1989) and Woodside, et al. ${ }^{14}$ (1991), in a five-year follow-up study, evaluated facial growth in children with severe nasopharyngeal obstruction, treated with adenoidectomy and compared it with the growth direction in a control sample with clear airways and matched for age and sex. Linder-Aronson, et al. tested the hypothesis that the establishment of nasal respiration in children with severe nasopharyngeal obstruction can be eliminated as a factor in determining mandibular growth direction. They observed that the adenoidectomy sample initially showed significantly longer lower face heights, and 5 years after the surgery they showed a more horizontal mandibular growth direction, however this finding was significant just for girls $(\mathrm{p}<0.02)$. Those children, who exhibited a changed breathing pattern postoperatively, were analyzed by Kerr et al. ${ }^{5}$ (1989), who found that there was some reversal of the initial tendency to a posterior rotation of the mandible. Woodside, et al. ${ }^{14}$ (1991) showed that the amount of mandibular growth was significantly greater in a group who had had adenoidectomy than in matched controls. On the other hand, in a longitudinal study, Vig et al. ${ }^{13}$ (1981) examined the relationship between facial morphology and nasal respiration. They observed that subjects with long faces had a higher mean value of nasal resistance, although the authors did not indicate the facial morphology to predict the diagnosis of nasal obstruction.

In recent years, the mandibular antegonial notch, a concavity in the inferior border of mandible, has been associated with different facial characteristics. Several researches conducted by Singer, et al. ${ }^{11}$ (1987) and Lambrechets, et al. ${ }^{7}$ (1996) explored the possibility that mandibular antegonial notch morphology might predict mandibular growth, and showed a reduced amount of mandibular growth, larger gonial angle, vertical growth direction and longer lower facial height in patients with a deep notch. These studies were based on findings of (Björk ${ }^{2}$ 1969, Björk ${ }^{3}$ 1968), who reported that mandibles with a forward growth tendency exhibited a pattern of surface resorption under the mandibular angle. The opposite pattern occurred in persons with a backward mandibular growth tendency, leading to concavity in the inferior border of the mandible known as the antegonial notch. On the other hand, Kolodziej, et al. ${ }^{6}$ (2002) observed that antegonial notch depth fails to provide sufficient indication of future facial growth to warrant its application as a growth predictor in a non-extreme population. Ali et al. ${ }^{1} 2005$ showed that condylar bone change might be related to antegonial and ramus notch depth. Salem et al. ${ }^{10} 2003$ further suggested that there is a decreased Spee curve depth and mandibular body length, when there is an increase in the surface areas of the antegonial notches.

The literature reveals the correlation between facial growth patterns, respiratory pattern and presence of mandibular antegonial notch. Based on this, the present study is undertaken with the purpose of providing answers to the following question: does the respiratory pattern have any influence on mandibular morphology or on growth patterns?

\section{MATERIAL AND METHODS}

The cephalometric material used in this study was obtained from the files of São Paulo City University, comprising 100 subjects of European descent (50 boys and 50 girls), ranging from 8 to 13 years of age. The pretreatment lateral cephalometric radiographs were traced including the skeletal landmarks shown in Table I and Figure 1. Landmarks corresponding to the method of measuring mandibular antegonial notch depth, as described by Singer, et al. ${ }^{11}$ (1987), were included in the protocol (Figure 2). The linear and angular cephalometric measurements are defined in Table II. The sample was classified into two groups: mouth-breathers $(n=52)$ and as nasal-breathers $(\mathrm{n}=48)$.

\section{Statistical analysis}

The mean and standard deviations were calculated for each parameter (Table IV). The difference between 
mean values of mouth and nasal breathing was evaluated by the use of Student $t$ test. Differences were considered statistically significant when $p$ value was found to be 0.05 or less.

\section{RESULTS}

Mean values for breathing patterns listed in Table III showed a statistically significant relationship for ANS$\mathrm{Me}$ and AN. The mouth breathers group presented greater values for ANS-Me and AN. The growth pattern measurements (NS.GoMe, Ns.Gn, FMA) showed high values for mouth breathing subjects, although they did not show statistical difference between groups. In other words, this data demonstrates association between mouth breathing pattern and deep antegonial notch and longer lower facial height.

\section{DISCUSSION}

The present study found an association between mouth breathing and increased lower facial height $(\mathrm{p}<0.05)$, which was expected based on previous studies. (Björk ${ }^{2}$ 1969, Lambrechts et al. ${ }^{7}$ 1996) Several researches Ali et al. ${ }^{1}$ 2005, Lambrechts et al. ${ }^{7}$ 1996) have shown the influence of mouth breathing on the vertical facial growth pattern. Ung et al. ${ }^{12}$ (1990) evaluated 49 subjects ranging from 10 to 16 years of age. Oral, nasal and total

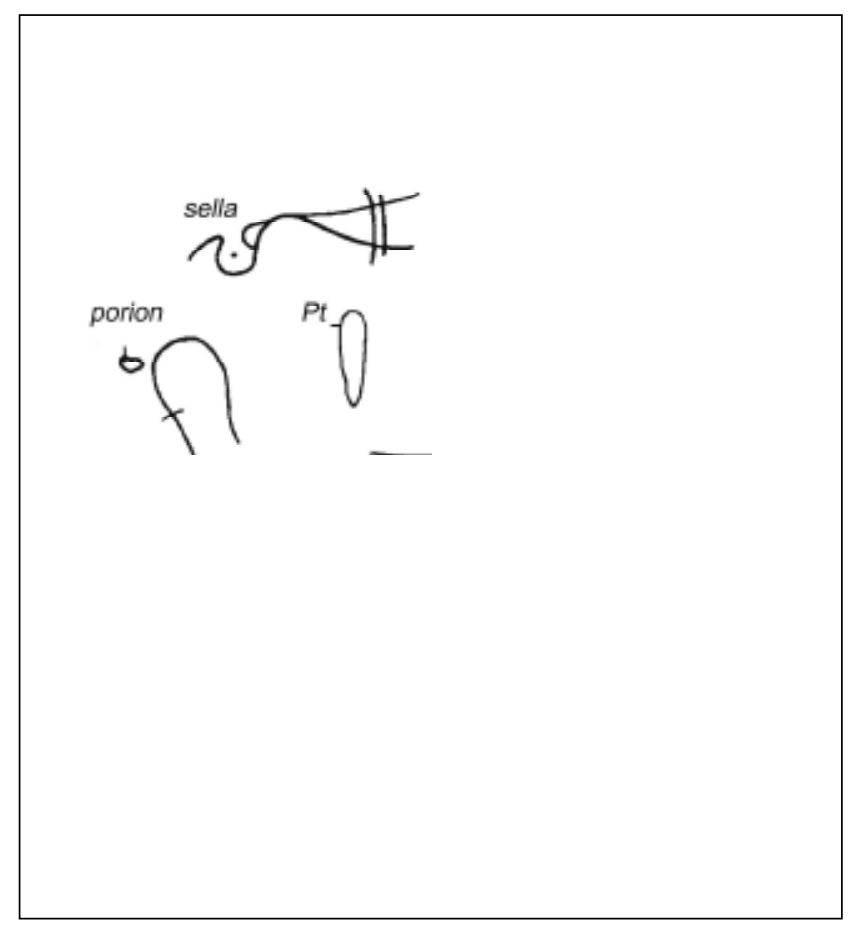

Figure 1 - Representative cephalometric landmarks airflow were measured at separate times by means of a head-out body plethysmograph technique and the values were compared with the subjects' and parents' subjective perceptions of their breathing modes. They observed that a subjective perception of mouth breathing was associated with increased anterior facial height and greater mandibular plane angles. In this study the breathing mode was evaluated by a clinical examination and the same result was observed: that the mouth-breathing group presented a greater lower anterior facial height. Fields, et al. ${ }^{4}$ (1991)in a study with 48 adolescents (11 to 17 years), also found that the long-faced subjects had significantly smaller nasal breathing components. Some studies evaluated a sample of 38 children from 7 to 12 years old, over a period of 5 years after adenoidectomy (Field et al. ${ }^{4}$ 1991, Kolodziej et al. ${ }^{6}$ 2002). LinderAronson et al. ${ }^{8}$ (1986) showed that girls with previous severe obstruction, presented a mandibular growth with more a horizontal direction after adenoidectomy than matched controls. The same sample was evaluated by Kerr et al. ${ }^{5}$ (1989) who observed a more anterior direction of symphyseal growth in the adenoidectomy group and by Woodside et al. ${ }^{14}$ (1991), who showed that the amount of mandibular growth was significantly greater in the group who had adenoidectomy.

The literature confirms the influence of breathing

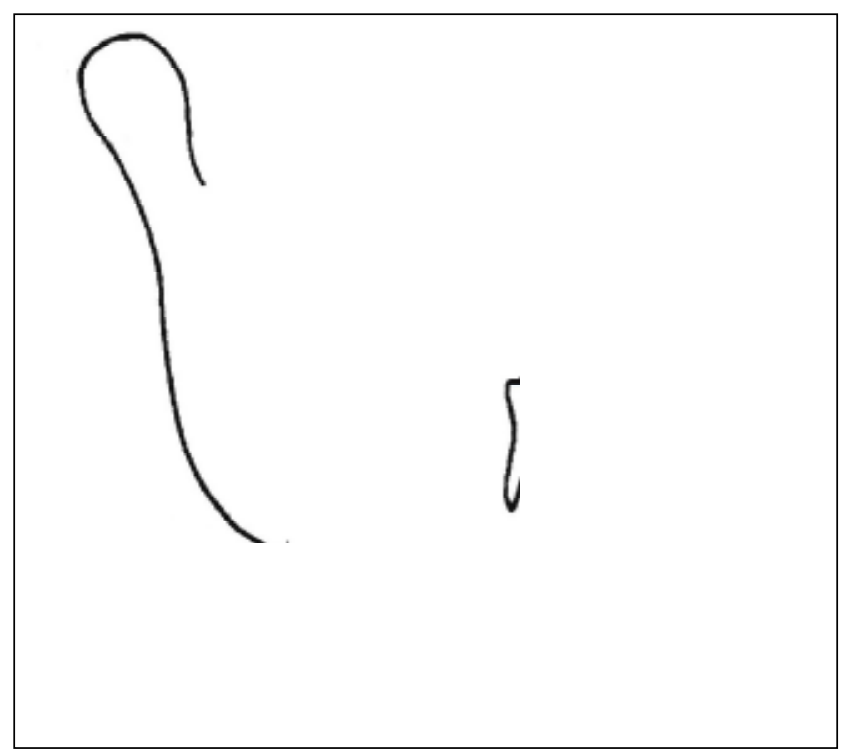

Figure 2 - Antegonial notch - greatest point of convexity in the line connecting anterior convexity point $(A C P)$ with inferior gonion (Igo) along the line perpendicular to the ACP-Igo line. 
pattern on craniofacial morphology and supports the fact that the breathing patterns can change the mandibular form. In individuals with a mouth-breathing pattern, diagnosis and treatment cannot be carried out by the orthodontist alone; these patients need interaction with the medical areas in order to improve their respiratory pattern.

The present study also pointed to an association between subjects with mouth breathing patterns and deep antegonial notches (Table III). However, the mandibular antegonial notch is associated with the mandibular growth direction.
Singer et al. ${ }^{11}$ (1987) and Lambrechts et al. ${ }^{7}$ (1996) reported significant differences between subjects with extremely deep ( $3 \mathrm{~mm}$ or $>$ ) or extremely shallow ( $1 \mathrm{~mm}$ or $<$ ) mandibular antegonial notches, with respect to being indicators of mandibular growth direction. They observed that the deep antegonial notch group reflected more vertical mandibular growth patterns resulting in longer anterior facial heights than the shallow notch group. However, the subjects of the present study sample displayed more normative facial characteristics than did those of Singer et al. ${ }^{11}$ (1987) and Lambrechts et al. ${ }^{7}$ (1996) as described by Kolodziej, et al. ${ }^{6}$ (2002).

Table I - Definition of cephalometric parameters identified in cephalograms

\begin{tabular}{|c|c|}
\hline Parameters & Definitions \\
\hline Sella $(S)$ & Midpoint of sella turcica \\
\hline Nasion $(\mathrm{N})$ & Junction of the nasal and frontal bones at the naso-frontal suture \\
\hline Orbitale & Most inferior point on the infra-orbital margin \\
\hline Anterior Nasal Spine (ANS) & $\begin{array}{c}\text { Most anterior point of the bony process of the maxilla at the lower margin } \\
\text { of the anterior nasal opening }\end{array}$ \\
\hline Basion (Ba) & $\begin{array}{l}\text { The most inferior posterior point on the anterior margin of the foramen } \\
\text { magnum }\end{array}$ \\
\hline Pogonion (Pg) & Most anterior point in the anterior outline of the symphysis \\
\hline Gnation (Gn) & Midpoint along the contour of the anterior outline of the symphysis \\
\hline Menton $(\mathrm{Me})$ & Most inferior point in the inferior outline of the symphysis \\
\hline \multicolumn{2}{|l|}{ Pterigomaxillar $(\mathrm{Pt})$} \\
\hline Gonion (Go) & Most superior posterior point of the fissure pterigomaxilar \\
\hline \multicolumn{2}{|c|}{ Most posterior inferior point of the mandible } \\
\hline Inferior Gonion (IGo) & $\begin{array}{l}\text { Point of the greatest convexity along the posterior-inferior border of the } \\
\text { mandible }\end{array}$ \\
\hline Anterior Convexity Point (ACP) & $\begin{array}{l}\text { Point of greatest convexity along the anterior-inferior border of the } \\
\text { mandible }\end{array}$ \\
\hline Antegonial Notch (AN) & Point of a deepest concavity between anterior convexity and inferior gonion \\
\hline Porion (Po) & Most superior point of the external auditory meatus \\
\hline Frankfort plane $(\mathrm{F})$ & A line connecting porion and orbitale \\
\hline Mandibular plane (MA) & A line connecting gnation and menton \\
\hline
\end{tabular}


Singer, et al. ${ }^{8}$ (1987) did report some findings based on longitudinal data. They also used a treated sample, which may have influenced actual growth. Lambrechts et al. ${ }^{7}$ (1996) used cross-sectional data in their investigation, and the use of notch depth as a true growth predictor could not be properly assessed, because growth can only be assessed by comparing at least 2 points in time. Kolodziej, et al. ${ }^{6}$ (2002) examined subjects without orthodontic treatment during the course of a long growth

Table II - Linear and angular measurements

\begin{tabular}{ll}
\hline \hline Linear measurements & Angular measurements \\
\hline 1. ANS - Me & 1. SN.Go-Me \\
2. An - ACP-Igo & 2. SN.Go-Gn \\
& 3. FMA \\
& 4. Ba.Pt-Gn \\
\hline \hline
\end{tabular}

Table III - Mean values \pm SD for variables of cephalometric parameters for mouth and nasal groups

\begin{tabular}{ccrcc}
\hline \hline \multirow{4}{*}{ Measurement } & $\begin{array}{c}\text { Mouth } \\
\text { breathing } \\
\text { XM } \pm \text { SD }\end{array}$ & $\begin{array}{c}\text { Nasal } \\
\text { breathing } \\
\text { XN } \pm \text { SD }\end{array}$ & t value & p \\
\hline \multirow{2}{*}{ ANS - Me } & 68.9 & 66.2 & \multirow{2}{*}{$24^{*}$} & $0,018^{*}$ \\
& 5.8 & 5.4 & & \\
SN.Go-Me & 37.9 & 37.4 & 0.4 & 0,69 \\
& 5.8 & 5.3 & & \\
SN.Go-Gn & 69.4 & 68.7 & 0.9 & 0,37 \\
& 4.0 & 3.4 & & \\
FMA & 29.8 & 28.1 & \multirow{2}{*}{1.8} & $0,0,075$ \\
& 4.4 & 5.1 & & \\
Ba.Pt-Gn & 88.1 & 90.0 & 0.8 & 0,426 \\
& 6.8 & 4.7 & & \\
An - ACP-IGo & 2.1 & 1.7 & $2.2 *$ & $0,03^{*}$ \\
\hline \hline
\end{tabular}

*Significant at 0.05 level period (at least 8.5 years) and concluded that antegonial notch depth fails to indicate future facial growth in a non-extreme population. This study was cross-sectional and retrospective, but also did not find an association between growth pattern and antegonial notching, considering NS.GoMe, NS.Gn, FMA and BaPtm.Gn.

The main finding of this study is that mouth-breathing pattern is associated with increased lower anterior facial height and deep antegonial notch and this data could be clinically useful. Based upon the results, it can be suggested that mandibular growth direction and form changes may occur in subjects with a mouth-breathing pattern, due to mandibular growth rotations, increased gonial angle, or increased Y-axis, and the mandibular antegonial notch might be deeper, due to mandibular flexion in the antegonial notch region by a masseter muscle imbalance. Up to now, the antegonial notch has been used to predict facial growth Lambrechts et al. ${ }^{7}$ (1996), Linder-Aronson, et al. ${ }^{8}$ (1986), Ung et al. ${ }^{12}$ (1990). It is suggested that antegonial notch could be used to help with the diagnosis of the breathing mode or it could be a marker in a subject who had a mouth-breathing pattern during childhood.

In the present study, a large sample would also have allowed correlations to be studied for a subset of patients, whose notch depths were extreme $(>3.0 \mathrm{~mm}$ or $<1.0 \mathrm{~mm}$ ) and an electromyographic exam might have elucidated the possible influence of muscle activity on the depth of the mandibular antegonial notch.

\section{CONCLUSIONS}

A statistically significant $(\mathrm{p} \leq 0.05)$ relationship existed between mouth-breathing patterns, deep antegonial notch and increased lower anterior facial height. It is concluded that mouth-breathing patients presented a greater anterior facial height and deeper antegonial notch. 


\section{REFERENCES}

1. Ali IM, Yamada K, Hanada K. Mandibular antegonial and ramusnotch depths and condylar bone change. J Oral Rebabil 2005 Jan; 32(1): 1-6.

2. Björk A. Prediction of mandibular growth rotation. Am J Orthod 1969 Jun; 55(6): 585-99.

3. Björk A. The use of metallic implants in the study of facial growth in children: method and application. Am J phys Anthropol 1968 Sep; 29(2): 243-54.

4. Fields HW, Warren DW, Black K, Phillips CL. Relationship between vertical dentofacial morphology and respiration in adolescents. Am J Orthod Dentofacial Orthop 1991Feb; 99(2): 147-54.

5. Kerr WJ, McWilliam JS, Linder-Aronson S, Mandibular form and position related to changed mode of breathing- a five-year longitudinal study. Angle Orthod 1989; 59(2): 91-6.

6. Kolodziej RP, Southard TE, Southard KA, Casko JS, Jakobsen JR. Evaluation of antegonial notch depth for growth prediction. Am J Orthod Dentofacial Orthop 2002 Apr; 121(4): 357-63.

7. Lambrechts, AH, Harris AM, Rossouw PE, Stander I. Dimensional differences in the craniofacial morphologies of groups with deep and shallow mandibular antegonial notching. Angle Orthod 1996; 66(4): 265-72.
8. Linder-Aronson S, Woodside DG, Lundstrom A. Mandibular growth direction following adenoidectomy. Am J Orthod 1986 Apr; 89(4): 273-84.

9. McNamara JA. Influence of respiratory pattern on craniofacial growth. Angle Orthod 1981 Oct; 51(4): 269-300.

10. Salem OH, Al-Sehaibany F, Preston CB. Aspects of mandibular morphology, with specific reference to the antegonial notch and the curve of Spee. J Clin Pediatr Dent. 2003; 27(3): 261-5.

11. Singer CP, Mamandras AH, Hunter WS. The depth of the mandibular antegonial notch as an indicator of mandibular growth potential. Am J Orthod Dentofacial Orthop 1987 Feb; 91(2): 117-24.

12. Ung N, Koenig J, Shapiro G, Trask G. A quantitative assessment of respiratory patterns and their effects on dentofacial development. Am J Orthod Dentofacial Orthop 1990 Dec; 98(6): 532-32.

13. Vig PS, Saver DM, Hall DJ, Warren DW. Quantitative evaluation of nasal airflow in relation to facial morphology. Am J Orthod. 1981 Mar; 79(3): 263-72.

14. Woodside DG, Linder-Aronson S, Lundstrom A, McWilliam JS. Mandibular and maxillary growth after changed mode of breathing. Am J Orthod Dentofacial Orthop 1991 Jul;100(1): 1-18.

Recebido em: 19/01/2009 Aceito em: 19/02/2009 